\title{
Osteoporotic Fracture
}

National Cancer Institute

\section{Source}

National Cancer Institute. Osteoporotic Fracture. NCI Thesaurus. Code C80097.

A pathologic bone fracture due to osteoporosis. It is generally caused by a fall from a standing height or lower and usually involves the spine, hip, or wrist. 